\title{
Modeling for PEFC MEAs Based on Reaction Rate on Pt Surface and Microstructures of Catalyst Layers
}

\author{
Nuttapol Limjeerajarus ${ }^{1,2}$, Yosuke Nishiyama ${ }^{2}$, \\ Hidenori OHASHI ${ }^{3}$, Taichi ITO $^{3}$ \\ and Takeo YAMAGUCHI ${ }^{2,3}$ \\ ${ }^{1}$ Department of Automotive Engineering, \\ Thai-Nichi Institute of Technology, \\ 1771/1 Pattanakarn, Suan Luang, Bangkok 10250, Thailand \\ ${ }^{2}$ Department of Chemical System Engineering, \\ The University of Tokyo, 7-3-1 Hongo, Bunkyo-ku, \\ Tokyo 113-8656, Japan \\ ${ }^{3}$ Chemical Resources Laboratory, Tokyo Institute of Technology, \\ 4259 Nagatsuta, Midori-ku, Yokohama-shi, \\ Kanagawa 226-8503, Japan
}

Keywords: Catalyst Layer, Modeling, ORR Activity, PEFCs, Secondary Pore

\begin{abstract}
A polymer electrolyte fuel cell membrane electrode assembly (PEFC MEA) model that focuses on the structural and reaction parameters of catalyst layers has been developed. The reaction and structural parameters were modeled independently by considering the oxygen reduction reaction (ORR) activity in terms of current per unit active surface area of $\mathrm{Pt}\left[\mathrm{A} \mathrm{cm}^{-2} \mathrm{Pt}\right]$. The catalyst layer models were constructed based on an assumption of cylindrical secondary pore structure, which was verified by measur-

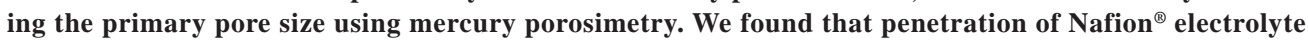
into the primary pores of $\mathrm{Pt} / \mathrm{C}$ catalysts was restricted, and thus diffusion and reaction in primary pores became negligible. Moreover, the experimental results demonstrated that for the same catalyst, ORR activity remained almost constant, irrespective of the agglomerate size (i.e., $2.7 \times 10^{-6} \mathrm{~A} \mathrm{~cm}^{-2}-\mathrm{Pt}^{\mathrm{at}} 60^{\circ} \mathrm{C}$ for Pt/C TEC10E50E in this study). This supported our idea that reaction parameters and structural parameters should be considered independently in PEFC modeling. The cell performance predicted with the developed model was satisfactorily accurate as compared to that obtained from experiments. As a result, the modeling developed in this study can be used to construct simple PEFC models that yield results with good accuracy and can be a useful tool for the development of PEFCs in future.
\end{abstract}

\section{Introduction}

Polymer electrolyte fuel cells (PEFCs) are considered one of the most promising power sources for future automobiles, stationary and portable power applications (Weber and Newman, 2004a; Stamenkovic et al., 2006). However, currently available PEFCs have not been completely commercial because of various problems related to their performance and production cost. The operation of PEFCs involves many complex phenomena and reactions, which affect their overall performance. These phenomena must be thoroughly investigated in order to improve, predict, and optimize the cell performance so that PEFCs can genuinely be applicable in such applications. However, experimental approaches are time-consuming, expensive and highly uncertain. As a result, modeling approaches that are less time-consuming, inexpensive and more versa-

Received on January 7, 2009; accepted on April 18, 2009. Correspondence concerning this article should be addressed to T. Yamaguchi (E-mail address: yamag@ res.titech.ac.jp). tile have recently played an important role in the development of PEFCs.

Most of the PEFC models developed so far can be categorized into three main types based on their considered dimension, namely through-plane (sandwich), in-plane, and along-channel dimensions. Typically, inplane and along-channel PEFC models are those focusing on water and heat transport phenomena in the diffusion layers (Lin et al., 2004; Acosta et al., 2006; You and Liu, 2006), gas flow channels (Meng and Wang, 2005; Wang and Wang, 2006), and electrolyte membrane (Thampan et al., 2000; Rowe and Li, 2001; Weber and Newman, 2004b). Since water and heat transports are more important in diffusion layers, gas flow channels, and electrolyte membrane, these models do not focus on reactions occurring in the catalyst layers.

Although water management in the catalyst layers of PEFCs is vital to PEFC modeling (Eikerling, 2006; Shah et al., 2006), electrochemical reaction in a thin component like the catalyst layer is more important when through-plane dimension is considered. 
Therefore, the through-plane (sandwich) models (Siegel et al., 2003; Wang et al., 2004; Karan, 2007) are those focusing on the electrochemical reaction occurring at pore levels in the catalyst layers.

Parameters corresponding to the catalyst layers can be divided into three categories: physical parameters, reaction parameters, and structural parameters. Physical parameters such as diffusion coefficient and proton conductivity, and reaction parameters such as oxygen reduction reaction (ORR) activity are inherent properties of each material, and thus they are independent of the structure of catalyst layers (primary and secondary pore size, porosity, agglomerate size, etc.). Therefore, once the material to be used in the PEFC is decided, the performance of PEFCs will be controlled only by the structural parameters. Among these parameters, a reaction parameter called ORR activity is very important as it determines the reaction rate of overall ORR and the output performance of the PEFC. However, previous PEFC models mentioned above have normally considered the ORR activity in terms of current per unit surface area of the electrode $\left[\mathrm{A} \mathrm{cm}^{-2}\right.$-electrode] or current per unit volume of the catalyst layer $\left[\mathrm{A} \mathrm{m}^{-3}\right.$ ] or current per unit volume of the catalyst agglomerate $\left[\mathrm{A} \mathrm{m}^{-3}\right.$-agglomerate]. In this way, the effect of catalyst structures such as agglomerate size, porosity, etc. is taken into account in the ORR activity. This contributes to a drawback that the effect of structural and reaction parameters cannot be clearly and independently analyzed, and this limits the versatility of the previous models.

In our recent work (Limjeerajarus et al., 2009), the ORR activity was calculated in terms of current per unit active surface area of $\mathrm{Pt}\left(i_{0, \mathrm{Pt}}\left[\mathrm{A} \mathrm{cm} \mathrm{cm}^{-2} \mathrm{Pt}\right]\right)$ in order to prove that $\mathrm{Pt}$ loading had no effect on the ORR activity. Hence, the idea of $i_{0, \mathrm{Pt}}$ was introduced in the present work for analyzing the structural and reaction parameters independently so as to make PEFC modeling more efficient that can be used to study the effect of each parameter on the cell performance.

In addition, investigation of the microstructures of the catalyst layer is a very important issue. The effect of catalyst agglomerate size on catalyst microstructures was investigated to verify the validity of an assumption of a cylindrical secondary pore structure, which was used in our modeling. A model of singlecell PEFC MEA was developed using the experimental results. Finally, the model was validated by comparing the results of cell performance obtained from simulation and experiments.

\section{Model Development}

\subsection{Model description and assumptions}

Since the catalyst layer is the most important component of PEFCs from the viewpoint of electrochemical reactions, the developed model focuses on the catalyst layers. The model is developed based on a cylindrical secondary pore structure, in which diffusion and reaction occurring inside the primary pores are assumed negligible. This assumption has been verified by measuring the primary pore size (presented later in Section 4.2). The observed primary pore size distribution indicates that in the case of $\mathrm{Pt} / \mathrm{C}$ catalysts, the penetration of Nafion ${ }^{\circledR}$ ionomer into the primary pores is restricted, and thus active Pt particles are at the surface of cylindrical secondary pores. As a result, the validity of the cylindrical secondary pore model is confirmed.

Then, the model of catalyst layers is connected to that of the electrolyte membrane to complete a onedimensional (sandwich direction), single-phase, and isothermal single-cell MEA modeling. Note that diffusion of gas species through the diffusion layer is considered to be the boundary condition.

The key assumptions in the model are described below.

- Diffusion and reaction in the primary pores inside catalyst agglomerates are negligible: This assumption is evidenced by experimental results, which show that in the case of $\mathrm{Pt} / \mathrm{C}$ catalysts with Nafion ${ }^{\circledR}$ as the electrolyte, the primary pore size is unaffected by agglomerate size. This implies that $\mathrm{Pt}$ particles inside the primary pores are not active, and thus diffusion and reaction in the primary pores can be neglected vis-à-vis those in the secondary pores. This issue is discussed in detail in Section 4.2.

- $\quad$ Structure of cylindrical secondary pores: On the basis of aforementioned assumption, utilizable Pt particles are on the surface of the secondary pores with uniform Pt utilization. The secondary pores are modeled to have a cylindrical structure, where the proton-conducting polymer is homogeneous in thickness, as shown in Figure 1. Gases in the secondary pores diffuse in the $x$-direction and the adsorbed gases diffuse in the radial direction of the cylinder.

- $\quad$ Single-phase or gas-phase flow: The aim of this work is to focus on the reaction and structural parameters of catalyst layers; therefore, liquid-phase water management is not considered in this model.

- Isothermal system: Non-isothermal models developed by other research groups indicated that the temperature distribution across $1-\mathrm{D}$ sandwich direction is normally uniform (around $1^{\circ} \mathrm{C}$ ), and thus the isothermal assumption is valid for sandwich models (Weber and Newman, 2004a).

1.2 Physico-electrochemical processes considered in secondary pores of the catalyst layer

As presented from the physicochemical viewpoint in Figure 1, the overall reaction and transport phenomena occurring in the secondary pores of the catalyst layers can be described in terms of the following five processes: 


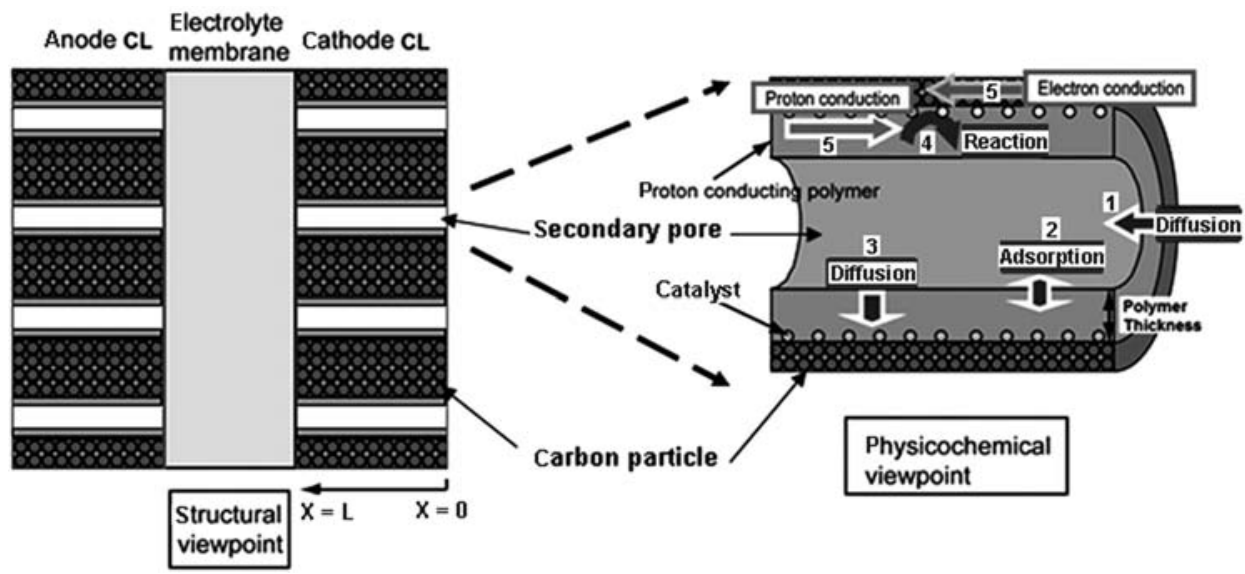

Fig. 1 Schematic illustration of the structural model of catalyst layers and the physico-electrochemical phenomena considered in the cylindrical secondary pore model

1. Binary gas diffusion into the secondary pores of the catalyst layer, as described by Fick's law.

2. Adsorption of fuel gases onto electrolyte at the gas-electrolyte film interface, in accordance with Henry's law.

3. Binary diffusion of the dissolved gases into the proton-conducting polymer, as described by Fick's law.

4. Electrochemical reaction on the surface of $\mathrm{Pt}$ at the three-phase boundary, as described by the Tafel equation.

5. Proton migration in the polymer and electron migration in carbon, in accordance with Ohm's law.

\section{Model Equations}

\subsection{Structural models of the catalyst layer}

We characterized the structural model of the catalyst layer on the basis of microscopic structural parameters such as the Pt particle radius, Pt density, carbon particle radius, and carbon density, and macroscopic structural parameters such as the catalyst layer thickness and active Pt surface area. The active Pt surface area is modeled by considering Pt utilization obtained from cyclic voltammetry (CV). The influences of the thickness of the catalyst layer and active Pt surface area on the cell performance are expressed as proton conduction/mass transfer and reaction rate, respectively.

Considering structure of the catalyst layer presented in Figure 2(a), catalyst layer thickness can be estimated on the assumption that the carbon particles are perfect spheres and are closely packed in a regular array.

The number of carbon particles in a single carbon sheet with a cross-sectional area of $1 \mathrm{~cm}^{2}, N_{\text {sheet }}$, can be expressed as a function of the radius of a carbon particle, $r_{\mathrm{cb}}$, as follows:

$$
N_{\text {sheet }}=\left(1-\varepsilon_{\mathrm{CL}}\right)\left(\frac{10^{-2}}{2 r_{\mathrm{cb}}}\right)^{2}
$$

where $\varepsilon_{\mathrm{CL}}$ is the porosity of the catalyst layer. $r_{\mathrm{cb}}$ can be obtained by transmission electron microscopy (TEM). The number of secondary pores within a given layer of secondary particles, $N_{\text {pore }}$, per unit surface area of the electrode $\left[\mathrm{cm}^{2}\right]$ is estimated by the following equation:

$$
N_{\text {pore }}=\varepsilon_{\mathrm{CL}}\left(\frac{10^{-4}}{\pi r_{\text {pore }}^{2}}\right)
$$

where $r_{\text {pore }}$ is the radius of the secondary pores, which can be obtained by bubble point tests.

Two macroscopic parameters, the $\mathrm{Pt} / \mathrm{C}$ mass ratio, $m$ [wt $\%$ ] and Pt loading, $S$ [g cm $\mathrm{g}^{-2}$-electrode], are introduced to correlate the macroscopic parameters with microscopic parameters. These two parameters depend on the type of Pt catalyst and the experimental conditions, respectively.

First, the weight of a carbon particle $\left(w_{\mathrm{cb}}\right)$ and the weight of a Pt particle $\left(w_{\mathrm{Pt}}\right)$ can be estimated as follows:

$$
w_{\mathrm{cb}}=\frac{4 \pi}{3} r_{\mathrm{cb}}^{3} \rho_{\mathrm{cb}} \quad \text { and } \quad w_{\mathrm{Pt}}=\frac{4 \pi}{3} r_{\mathrm{Pt}}^{3} \rho_{\mathrm{Pt}}
$$

If a carbon particle can support $n$ Pt particles, the $\mathrm{Pt} / \mathrm{C}$ mass ratio $m$ can be expressed as

$$
m=\frac{n \cdot w_{\mathrm{Pt}}}{w_{\mathrm{cb}}+n \cdot w_{\mathrm{Pt}}} \times 100
$$



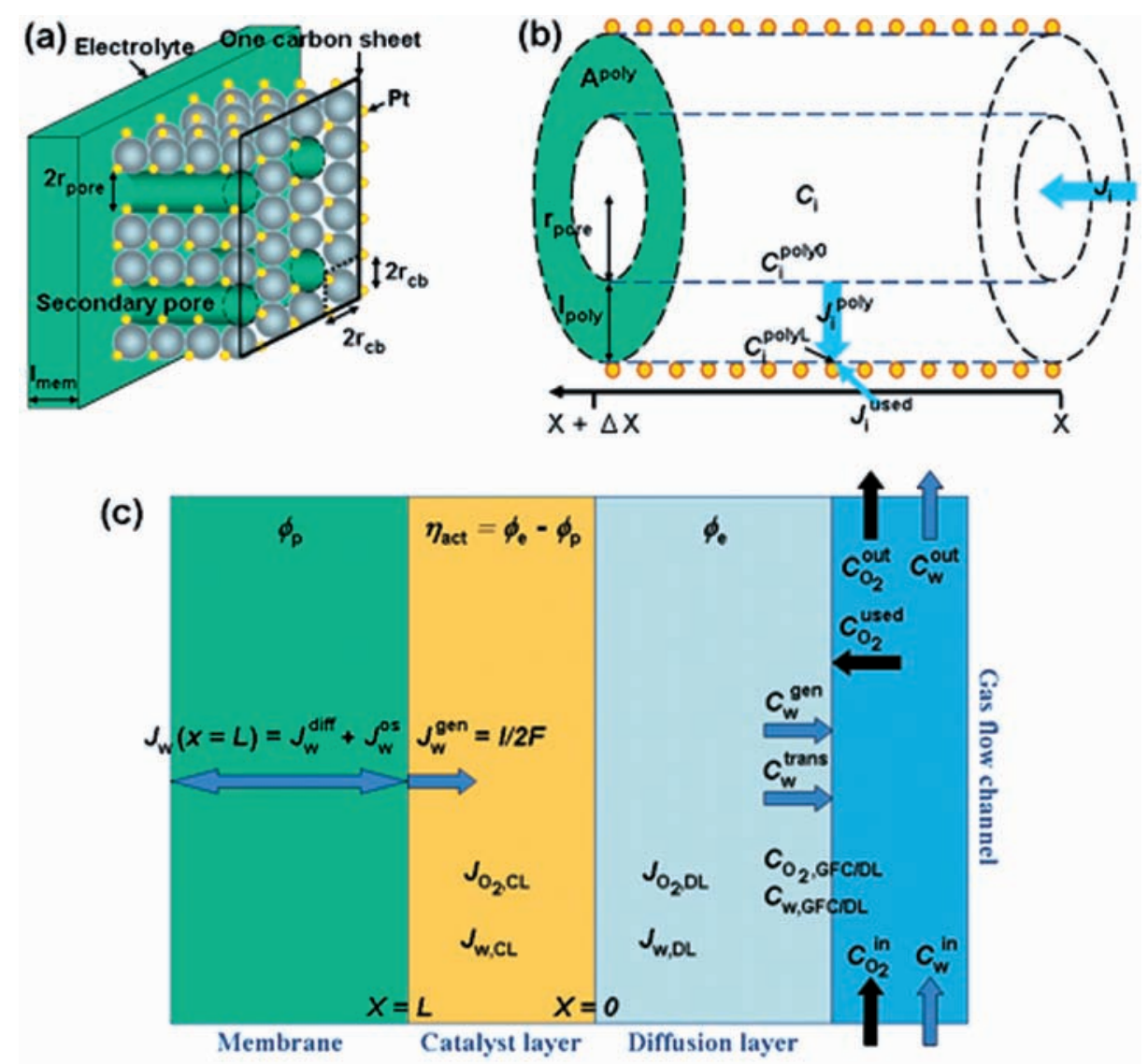

Fig. 2 Schematic illustrations of (a) characterization of structure of the catalyst layer, (b) transports of specie fluxes in a secondary pore, and (c) boundary conditions on the cathode side of the model

Thus,

$$
n=\frac{w_{\mathrm{cb}}}{w_{\mathrm{Pt}}} \cdot \frac{m}{100-m}
$$

The Pt loading $(S)$ can be expressed as follows:

$$
S=w_{\mathrm{Pt}} \times N
$$

where $N$ represents the number of introduced Pt particles per geometric area of the electrode in $\mathrm{cm}^{2}$. Therefore, the number of carbon particles introduced on the electrode is equal to $N / n$. The number of carbon particle layers, $N_{\text {layer }}$, can be obtained by dividing $N / n$ by $N_{\text {sheet }}$. Thus, the thickness of the catalyst layer, $L$, can be estimated as follows:

$$
L=\frac{N / n}{N_{\text {sheet }}} \times 2 r_{\text {cb }}
$$

To express the thickness of the catalyst layer $L$ in terms of two macroscopic parameters, $S$ and $m$, we can combine the equations mentioned above to yield

$$
L=\frac{6}{\pi} \times 10^{4} \cdot \frac{S(100-m)}{\left(1-\varepsilon_{\mathrm{CL}}\right) \cdot m \cdot \rho_{\mathrm{cb}}}
$$

Hence, the pore length can be calculated by including the effect of tortuosity of the catalyst layer $\tau_{\mathrm{CL}}$, which is typically estimated from Bruggeman's expression $\left(\tau=\varepsilon^{-0.5}\right)$, as follows:

$$
\text { Pore length }=\tau_{\mathrm{CL}} \times L
$$

\subsection{Mass transport models in the cathode catalyst layer}

The mass balance equations described in this section are developed on the basis of the properties of a single cylindrical secondary pore. The gas concentration, $C_{i}$, of species $i$ in a secondary pore in the catalyst layer is governed by the following mass balance equation:

$$
\pi r_{\text {pore }}^{2} \frac{\partial J_{i}}{\partial x}+\pi r_{\text {pore }}^{2} \frac{\partial C_{i}}{\partial t}=-\frac{U_{\mathrm{Pt}} \cdot S \cdot A_{\mathrm{s}}}{N_{\text {pore }}} \cdot \frac{v(x)}{z F}
$$


where $J_{i}$ is the reactant gas flux of species $i$ diffusing in the pore $\left[\mathrm{mol} \mathrm{m}^{-2} \mathrm{~s}^{-1}\right.$ ]. $x$ is the normalized characteristic length, i.e. the thickness of the catalyst layer. $U_{\mathrm{Pt}}$ stands for Pt utilization measured by CV. As represents the specific surface area of $\mathrm{Pt}\left[\mathrm{m}^{2} \mathrm{~g}^{-1}\right]$, which is determined by the $\mathrm{CO}$ adsorption method and provided by the catalyst manufacturer. $v$ is the reaction rate $\left[\mathrm{A} \mathrm{m}^{-2}\right]$. $z$ denotes the number of electrons transferred per reaction. Therefore, the values of $z$ for oxygen reduction and hydrogen oxidation are 4 and -2 , respectively. Based on our assumptions of binary gas diffusion, the Stefan-Maxwell equation for multi-component diffusion can be reduced to Fick's law for binary gas diffusion. Thus $J_{i}$ (refer to process 1 in Figure 1) is defined as follows:

$$
J_{i}=-\frac{\varepsilon_{\mathrm{CL}}}{\tau_{\mathrm{CL}}} D_{\mathrm{i}}^{\text {gas }} \frac{\partial C_{i}}{\partial x}
$$

where $D_{i}^{\text {gas }}$ is the gas diffusion coefficient of species $i$ $\left[\mathrm{m} \mathrm{s}^{-1}\right]$.

The reactant gases dissolve in liquid water in the polymer (refers to process 2 in Figure 1). Hence, the solubility of gas in liquid water obeys Henry's law. According to Henry's law, the solubility of a gas in liquid is proportional to the partial pressure of the gas. The solubility here is expressed in terms of the molar ratio $y$ in the solvent. We can also obtain the dependence of solubility on temperature expressed as follows:

$$
\ln y=\gamma_{1}+\frac{\gamma_{2}}{(T / 100)}+\gamma_{3} \ln \left(\frac{T}{100}\right)
$$

In this correlation, the partial pressure of the gas is $101.3 \mathrm{kPa}$. The values of dimensionless parameters $\gamma_{1}, \gamma_{2}$ and $\gamma_{3}$ are shown in Table 1. For simplification of the calculation in this model, it is preferable to use $C_{i}$ than the molar ratio. Thus, a formula for converting the molar ratio to concentration must be developed. The molar ratio of oxygen, $y_{\mathrm{O}_{2}}$, can be written as

$$
y_{\mathrm{O}_{2}}=\frac{g_{\mathrm{O}_{2}}}{g_{\mathrm{O}_{2}}+g_{\mathrm{w}}} \cong \frac{g_{\mathrm{O}_{2}}}{g_{\mathrm{w}}}
$$

This is because the molar number of oxygen, $g_{\mathrm{O}_{2}}$, is considerably smaller than that of water $g_{\mathrm{w}}$ and is neglected in the denominator. Using the Eq. (15), the formula for the concentration in the solvent can be obtained:

$$
C_{\mathrm{O}_{2}}^{\mathrm{s}}=\frac{g_{\mathrm{O}_{2}}}{\mathrm{~g}_{\mathrm{w}}} \cdot \frac{\rho_{\mathrm{H}_{2} \mathrm{O}}}{\mathrm{M} \cdot \mathrm{W} \cdot \cdot_{\mathrm{H}_{2} \mathrm{O}}}=y_{\mathrm{O}_{2}} \cdot \frac{\rho_{\mathrm{H}_{2} \mathrm{O}}}{\mathrm{M} \cdot \mathrm{W} \cdot \mathrm{H}_{2} \mathrm{O}}
$$

Table 1 Solubility parameter of gases dissolved in water (Society of Chemical Engineers, Japan, 1999)

\begin{tabular}{lcccc}
\hline Gas/solvent & $\gamma_{1}$ & $\gamma_{2}$ & $\gamma_{3}$ & Temperature $[\mathrm{K}]$ \\
\hline $\mathrm{O}_{2} /$ water & -66.735 & 87.476 & 24.453 & $273-348$ \\
$\mathrm{H}_{2} /$ water & -48.161 & 55.284 & 16.889 & $273-353$ \\
\hline
\end{tabular}

where $C_{\mathrm{O}_{2}}^{\mathrm{s}}$ is the oxygen concentration in the solvent at a pressure of $1 \mathrm{~atm}$. Therefore, the concentration of $\mathrm{O}_{2}$ at the gas-electrolyte film interface, $C_{\mathrm{O}_{2}}^{\text {poly0 }}$, is expressed by

$$
C_{\mathrm{O}_{2}}^{\text {poly0 }}=\left(y_{\mathrm{O}_{2}} \cdot \frac{\rho_{\mathrm{H}_{2} \mathrm{O}}}{\mathrm{M} \cdot \mathrm{W} \cdot \cdot_{\mathrm{H}_{2} \mathrm{O}}}\right) \times \frac{C_{\mathrm{O}_{2}} R T}{P}
$$

where $P$ denotes atmospheric pressure. $C_{\mathrm{O}_{2}} R T / P$ refers to the actual partial pressure of $\mathrm{O}_{2}[\mathrm{~Pa}]$.

Assuming that all diffusion fluxes reaching the three-phase boundary are completely consumed by reaction, the mass balance equation in the polymer phase in the radial direction of a secondary pore can be expressed as follows:

$$
2 \pi r_{\text {pore }} \frac{D_{\mathrm{i}}^{\text {poly }}}{l^{\text {poly }}}\left[C_{\mathrm{i}}^{\text {poly0 }}(x)-C_{\mathrm{i}}^{\text {polyL }}(x)\right]=\frac{U_{P t} \cdot S \cdot A_{\mathrm{s}}}{N_{\text {pore }}} \cdot \frac{v(x)}{z F}
$$

According to the schematic illustration of species fluxes in a secondary pore (Figure $2(\mathbf{b})$ ), the term on the left-hand side of Eq. (16) describes the diffusion fluxes of dissolved gases through the electrolyte polymer $J_{i}^{\text {poly }}$ based on process 3 shown in Figure 1 . The term on the right-hand side Eq. (16) refers to the flux of the gases used in the electrochemical reaction at the three-phase boundary $J_{i}^{\text {used }}$ (process 4 in Figure 1).

Typically, the ORR rate is governed by the Tafel equation, and the ORR activity is considered in terms of current per unit surface area of the electrode or current per unit volume of the agglomerate. However, in the present work, ORR activity is expressed in terms of current per unit active Pt surface area so that the reaction model becomes independent of the effect of structural parameters.

$$
v(x)=i_{0, \mathrm{Pt}} \frac{C_{\mathrm{O}_{2}}^{\mathrm{polyL}}(x)}{C_{\text {ref }}} \exp \left[\frac{\alpha F}{R T} \eta_{\mathrm{act}}(x)\right]
$$

where $i_{0, \mathrm{Pt}}$ and $\alpha$ are the ORR activity per unit active Pt surface area $\left[\mathrm{A} \mathrm{cm}^{-2}-\mathrm{Pt}\right]$ and the charge transfer coefficient, respectively. $C_{\mathrm{O}_{2}}^{\text {polyL }}$ represents the $\mathrm{O}_{2}$ concentration at the electrolyte-Pt particle interface at the three-phase boundary, and $C_{\text {ref }}$ represents the reference $\mathrm{O}_{2}$ concentration. 
The migration of protons in the polymer phase and electrons in the electron conductive phase, i.e., carbon black (refer to process 5 in Figure 1), obeys Ohm's law:

$$
\begin{aligned}
& i_{\mathrm{e}}=-\frac{\sigma_{\mathrm{e}} A^{\mathrm{e}}}{\tau_{\mathrm{CL}}} \frac{\partial \Phi_{\mathrm{e}}}{\partial x} \\
& i_{\mathrm{p}}=-\frac{\sigma_{\mathrm{p}} A^{\text {poly }}}{\tau_{\mathrm{CL}}} \frac{\partial \Phi_{\mathrm{p}}}{\partial x}
\end{aligned}
$$

where $i_{\mathrm{e}}$ and $i_{\mathrm{p}}$ are the electron and proton current densities in a secondary pore, respectively. $\sigma_{\mathrm{e}}$ and $\sigma_{\mathrm{p}}$ are the electron and proton conductivities, respectively. $\Phi_{\mathrm{e}}$ and $\Phi_{\mathrm{p}}$ are the local electronic and protonic potentials, respectively. The cross-sectional area of proton conduction per pore, $A^{\text {poly }}$, is defined by the following equation:

$$
A^{\text {poly }}=\pi\left(r_{\text {pore }}+l^{\text {poly }}\right)^{2}-\pi r_{\text {pore }}^{2}
$$

and $A^{\mathrm{e}}$ is the cross-sectional area of electron conduction per pore. The ohmic drop caused by electron conduction is considered to be negligible; hence, $A^{\mathrm{e}}$ is set to 1 (sufficiently large value).

The conservation of current can be described by Kirchhoff's law:

$$
i_{\mathrm{e}}+i_{\mathrm{p}}=\frac{I}{N_{\text {pore }}}
$$

No protons are generated at the diffusion layer/ catalyst layer interface $(x=0)$, and no electrons are produced at the catalyst layer/electrolyte membrane interface $(x=L)$. Therefore, the following boundary conditions for current density are obtained:

$$
\begin{aligned}
& i_{\mathrm{p}}(x=0)=0 \\
& i_{\mathrm{e}}(x=L)=0
\end{aligned}
$$

When the electrochemical reaction takes place, the electrode potential deviates from the equilibrium potential, and the local activation overpotential in the cathode is defined as follows:

$$
\eta_{\text {act }}(x)=\Phi_{\mathrm{e}}(x)-\Phi_{\mathrm{p}}(x)
$$

The mass balance of the proton current density can be written as follows:

$$
\frac{\partial i_{\mathrm{p}}(x)}{\partial x}=\frac{U_{\mathrm{Pt}} \cdot S \cdot A_{\mathrm{s}}}{N_{\text {pore }}} \cdot v(x)
$$

\subsection{Boundary conditions for each gas}

The boundary conditions and transport phenomena corresponding to the cathode-side MEA are described in Figure 2(c). Assuming that a gas flow channel behaves as a continuous stirred-tank reactor, the $\mathrm{O}_{2}$ concentration at the gas flow channel/diffusion layer interface on the cathode side, $C_{\mathrm{O}_{2}, \mathrm{GFC} / \mathrm{DL}}$, is equal to that at the outlet of the gas flow channel. Therefore, $C_{\mathrm{O}_{2}, \mathrm{GFC} / \mathrm{DL}}$ can be determined from the mass balance in the gas flow channel as follows:

$$
\begin{aligned}
& C_{\mathrm{O}_{2}, \mathrm{GFC} / \mathrm{DL}}=C_{\mathrm{O}_{2}}^{\text {out }}=C_{\mathrm{O}_{2}}^{\text {in }}-C_{\mathrm{O}_{2}}^{\text {used }} \\
& C_{\mathrm{O}_{2}, \mathrm{GFC} / \mathrm{DL}}=\left(\frac{P^{\mathrm{t}}}{R T} \times \frac{101.3-P_{\mathrm{bub}}}{101.3}\right)-\left(\frac{I}{4 F} \cdot \frac{A}{U}\right)
\end{aligned}
$$

where $A$ is the geometric area of the electrode $\left(5 \mathrm{~cm}^{2}\right.$ in this work). $U$ is the flow rate of the supplied gas $\left[\mathrm{m}^{3} \mathrm{~s}^{-1}\right]$. $P^{\mathrm{t}}$ is the total pressure of water and $\mathrm{O}_{2}$ in $\mathrm{Pa}$, and $P_{\text {bub }}$ is the water saturation pressure $[\mathrm{kPa}]$ at the temperature of the bubbler $T_{\text {bub }}\left[{ }^{\circ} \mathrm{C}\right]$. The dependence of $P_{\text {bub }}$ on $T_{\text {bub }}$ can be expressed by Antoine's equation as given below (Society of Chemical Engineers, Japan, 1999):

$$
\log P_{\text {bub }}=7.07406-\frac{1657.46}{227.02+T_{\text {bub }}}
$$

Consequently, the concentration of $\mathrm{O}_{2}$ at the diffusion layer/catalyst layer interface $(x=0)$ on the cathode side can be calculated by Fick's law as

$$
J_{\mathrm{O}_{2}, \mathrm{DL}}=-\frac{\varepsilon_{\mathrm{DL}}}{\tau_{\mathrm{DL}}} D_{\mathrm{O}_{2}}^{\mathrm{gas}} \frac{\left[C_{\mathrm{O}_{2}}(x=0)-C_{\mathrm{O}_{2}, \mathrm{GFC} / \mathrm{DL}}\right]}{l_{\mathrm{DL}}}
$$

Similarly, the boundary condition can be obtained from the water flux conservation as follows:

$$
\begin{aligned}
C_{\mathrm{w}, \mathrm{GFC} / \mathrm{DL}} & =C_{\mathrm{w}}^{\mathrm{out}}=C_{\mathrm{w}}^{\mathrm{in}}+C_{\mathrm{w}}^{\mathrm{gen}}+C_{\mathrm{w}}^{\mathrm{trans}} \\
C_{\mathrm{w}, \mathrm{GFC} / \mathrm{DL}} & =\left(\frac{P^{\mathrm{t}}}{R T} \times \frac{P_{\mathrm{bub}}}{101.3}\right)+\left(\frac{I}{2 F} \cdot \frac{A}{U}\right)+\left(J_{\mathrm{w}}^{\mathrm{trans}} \times \frac{A}{U}\right)
\end{aligned}
$$

where $J_{\mathrm{w}}{ }^{\text {trans }}$ is the net water flux transmitted through the membrane owning to back-diffusion and electroosmotic force. $J_{\mathrm{w}}{ }^{\text {trans }}$ is equal to the flux at the catalyst layer/electrolyte membrane interface $J_{\mathrm{w}}(x=L)$. Consequently, the concentration of water at the diffusion layer/catalyst layer interface, $C_{\mathrm{w}}(x=0)$, on the cathode side can be calculated by Fick's law as follows: 


$$
J_{\mathrm{w}, \mathrm{DL}}=-\frac{\varepsilon_{\mathrm{DL}}}{\tau_{\mathrm{DL}}} D_{\mathrm{w}}^{\mathrm{gas}} \frac{\left[C_{\mathrm{w}}(x=0)-C_{\mathrm{w}, \mathrm{GFC} / \mathrm{DL}}\right]}{l_{\mathrm{DL}}}
$$

where $D_{\mathrm{w}}{ }^{\text {gas }}$ is the diffusion coefficient of water in the gas phase.

At the catalyst layer/electrolyte membrane interface $(x=L)$, the $\mathrm{O}_{2}$ flux caused by a concentration gradient across the membrane is very small and is plausibly negligible. Thus, the following boundary condition for $\mathrm{O}_{2}$ can be obtained:

$$
J_{\mathrm{O}_{2}}(x=L)=0
$$

Considering the water flux at the catalyst layer/ electrolyte membrane interface $(x=L)$, two types of water flux exist: one due to the gradient of water activity across the membrane, and the other due to electroosmotic drag:

$$
J_{\mathrm{w}}(x=L)=J_{\mathrm{w}}^{\mathrm{diff}}+J_{\mathrm{w}}^{\mathrm{os}}
$$

where $J_{\mathrm{w}}{ }^{\text {os }}$ denotes the water flux caused by electroosmotic drag. At a constant cell temperature, $J_{\mathrm{w}}$ os is proportional to the cell current density $I$ and can be expressed as

$$
J_{\mathrm{w}}^{\mathrm{os}}=\xi \frac{I}{F}
$$

where $\xi$ is the electro-osmotic drag coefficient of water, which depends only on temperature. The relationship between $\xi$ and temperature is expressed by a polynomial approximation (Ren and Gottesfeld, 2001):

$$
\xi=1.0 \times 10^{-4} T^{2}+0.015 T+1.6
$$

However, the abovementioned relationship is determined using a fully hydrated membrane in equilibrium with liquid water, and it has experimentally been determined that the $\xi$ decreases in partially hydrated membranes (Springer et al., 1991). Thus, the electroosmotic drag coefficient in a partially hydrated membrane, $\xi^{\prime}$, is assumed to be linearly proportional to the water content $\lambda$ :

$$
\xi^{\prime}=v \lambda \xi
$$

where $v$ represents the proportionality factor. Since it is difficult to estimate the diffusion coefficient for a partial hydration, $v$ is determined using a fitting procedure so that the ohmic loss in the electrolyte membrane is accurately determined.

It is important to consider the physical parameters as a function of $\lambda$, which affects the cell performance. Proton conductivity is largely dependent on $\lambda$. The fol- lowing equation (Springer et al., 1991) expresses the proton conductivity $\left[\mathrm{S} \mathrm{cm}^{-1}\right]$ of Nafion ${ }^{\circledR}$ as a function of temperature $[\mathrm{K}]$ and $\lambda$ :

$$
\sigma_{\text {mem }}=(0.005139 \lambda-0.00326) \exp \left[1268\left(\frac{1}{303}-\frac{1}{T}\right)\right]
$$

The relationship between $\lambda$ and water activity, $a$, can be measured at 30 and $80^{\circ} \mathrm{C}$ as follows (Springer et al., 1991; Hinatsu et al., 1994):

$$
\lambda= \begin{cases}0.043+17.81 a-39.85 a^{2}+36 a^{3} & \left(30^{\circ} \mathrm{C}\right) \\ 0.30+10.8 a-16.0 a^{2}+14.1 a^{3} & \left(80^{\circ} \mathrm{C}\right)\end{cases}
$$

At temperatures between 30 and $80^{\circ} \mathrm{C}$, the $\lambda$ is estimated as a function of water activity by linear interpolation. In this model, the water activity is estimated from the concentration of water gas, $C_{\mathrm{w}}{ }^{\text {gas }}$, as follows:

$$
a=\frac{C_{\mathrm{w}}^{\mathrm{gas}} R T}{P^{\mathrm{t}} \times P_{\text {bub }} / 101.3}
$$

\subsection{Formulation of hydrogen crossover}

A small amount of hydrogen gas is transported from the anode to the cathode through the electrolyte membrane. This hydrogen gas is considered to react directly with $\mathrm{O}_{2}$ on the cathodic catalyst surface, thereby decreasing the efficiency of electricity generation. This phenomenon of waste hydrogen passing through the electrolyte is known as hydrogen crossover, which obeys Fick's law. Hydrogen crossover reduces the theoretical electromotive force $E_{0}$ as the current density produced cannot be taken to the external circuit. $E_{0}$ can be estimated from the Nernst equation, and its estimated value is $1.23 \mathrm{~V}$ under standard conditions ( $1 \mathrm{~atm}$ and $25^{\circ} \mathrm{C}$ ). To take the effect of hydrogen crossover on cathode polarization into consideration in the modeling, it was assumed that all the hydrogen reaching the cathode reacts electrochemically on the catalyst, and this reaction proceeds concurrently with $\mathrm{O}_{2}$ reduction. Based on above assumptions, the parasitic current generated by cathodic hydrogen oxidation, $I_{\text {cross }}$, can be obtained from the hydrogen crossover flux $J_{\mathrm{H}_{2}}$, which is calculated by Fick's law.

$$
I_{\text {cross }}=2 F J_{\mathrm{H}_{2}}
$$

Because of the existence of a parasitic current, the effective cathodic current density, $I^{\mathrm{eff}}$, needed to sustain a load current density $I$ is obtained by:

$$
I^{\mathrm{eff}}=I+I_{\text {cross }}
$$


The effect of $I_{\text {cross }}$ on the cathode overpotential is accounted for by substituting $I^{\text {eff }}$ for $I$ in the Tafel equation (Murgia et al., 2003) $\eta_{\text {act }}=b \ln I-b \ln i_{0}$.

Hence, we obtain

$$
\eta_{\mathrm{act}}^{\prime}=b \ln \left(\frac{I+I_{\mathrm{cross}}}{i_{0}}\right)
$$

where $b$ is the Tafel slope, and $i_{0}$ is exchange current density [A $\mathrm{cm}^{-2}$-electrode]. $\eta_{\text {act }}^{\prime}$ can be considered to be the sum of the cathodic activation overpotential, $\eta_{\text {act }}$, and overpotential caused by hydrogen crossover, $\eta_{\text {cross }}$. The two overpotentials can be distinguished mathematically as follows:

$$
\begin{aligned}
\eta_{\text {act }}^{\prime} & =\eta_{\text {cross }}+\eta_{\text {act }}=b \ln \left(\frac{I+I_{\text {cross }}}{i_{0}}\right) \\
& =b \ln \left(\frac{I+I_{\text {cross }}}{I} \times \frac{I}{i_{0}}\right) \\
& =b \ln \left(\frac{I+I_{\text {cross }}}{I}\right)+b \ln \left(\frac{I}{i_{0}}\right)
\end{aligned}
$$

The first term in the final equation corresponds to the overpotential caused by hydrogen crossover when the current density is not equal to zero. When the current density is equal to zero, $\eta_{\text {cross }}$ can be calculated using the following equation:

$$
\eta_{\text {cross }}=b \ln \left(\frac{I_{\text {cross }}}{i_{0}}\right)
$$

We have also considered the effect of hydrogen crossover on the output voltage $E$. Since the anodic overpotential is negligible owning to the rapid hydrogen oxidation reaction, the $E$ can be calculated from the following equation.

$$
E=E_{0}-\eta_{\mathrm{IR}}-\eta_{\mathrm{act}}-\eta_{\text {cross }}
$$

where $E_{0}$ is the theoretical electromotive force, $\eta_{\text {act }}$ is the cathode activation overpotential, $\eta_{\mathrm{IR}}$ is the ohmic loss in the electrolyte membrane and $\eta_{\text {cross }}$ is the overpotential caused by hydrogen crossover. $E_{0}$ is estimated from the reactant gas conditions (absolute temperature $T$ and pressure $P$ ) using the following equation (Maggio et al., 2001).

$$
E_{0}=1.23-0.9 \times 10^{-3}(T-298)+\frac{R T}{4 F} \ln \left(P_{\mathrm{H}_{2}}^{2} \cdot P_{\mathrm{O}_{2}}\right)(46)
$$

\subsection{Electrolyte membrane model}

The ohmic overpotential in an electrolyte membrane, $\eta_{\mathrm{IR}}$, can be described by Ohm's law as follows:

$$
\eta_{\mathrm{IR}}=\frac{l_{\mathrm{mem}}}{\sigma_{\mathrm{mem}}} I
$$

where $l_{\text {mem }}$ denotes the thickness of the electrolyte membrane, and $\sigma_{\text {mem }}$ is the proton conductivity of the membrane. In the model, proton conductivity at the electrolyte membrane/cathode catalyst layer interface ( $x=$ $L)$ can be calculated from the water activity. Thus, the value of proton conductivity $\sigma_{\mathrm{p}}(x=L)$ can be calculated under certain operational conditions. However, $\sigma_{\text {mem }}$ is not identical to $\sigma_{\mathrm{p}}(x=L)$ because water activity across the membrane varies with the direction of the thickness-axis, and this leads to a change in $\sigma_{\mathrm{p}}$. Therefore, the value of $\sigma_{\text {mem }}$ is estimated using the arithmetic average of $\sigma_{\mathrm{p}}(x=L)$ and the proton conductivity at the electrolyte membrane/anode catalyst layer interface, $\sigma_{\mathrm{p}}$ (anode side), as a representative value:

$$
\sigma_{\text {mem }}=\frac{\sigma_{\mathrm{p}}(x=L)+\sigma_{\mathrm{p}}(\text { anode side })}{2}
$$

\subsection{Anode model}

The anode model is similar to the cathode model, but in this case, the value of the exchange current density is assumed to be large enough so that the anodic activation overpotential becomes negligible.

\subsection{Simulation}

The developed mathematical models are divided into three submodels; cathode, electrolyte membrane, and anode. These three submodels are combined and model simulation is carried out using an implicit method on Microsoft Visual C++. Finally, the cell performance was predicted and compared with that obtained from experiments.

\section{Experimental Section}

\subsection{Preparation of MEAs}

Vulcan X-72 carbon ink was homogenized for 20 min and printed on Teflon-coated carbon paper (ECTP1-060, ElectroChem, Inc.) to form diffusion backings. Carbon-supported Pt catalyst powder supplied by Tanaka Kikinzoku Co. Ltd. (TEC10E50E; Pt particle size: 2-3 nm; Pt/C ratio: $46.5 \mathrm{wt} \%$ ) was used as the catalyst for both anode and cathode. The catalyst ink was homogenized for different periods of time, namely 5, 30, 60 and $90 \mathrm{~min}$, to control the catalyst agglomerate size. The catalyst ink was then printed on the diffusion backings by the screen-printing to make catalyst electrodes.

Nafion ${ }^{\circledR} 112$ (thickness: $50 \mu \mathrm{m}$ ) was employed as the electrolyte membrane of the MEAs. The membrane was boiled in $1 \mathrm{M}$ nitric acid at $90^{\circ} \mathrm{C}$ for $1-1.5 \mathrm{~h}$ to remove organic impurities, and was then rinsed in deionized water at $90^{\circ} \mathrm{C}$ for $1 \mathrm{~h}$.

Finally, the anode and cathode electrodes with dimensions of $2.25 \mathrm{~cm} \times 2.25 \mathrm{~cm}$ (a total geometric 
electrode area of $5 \mathrm{~cm}^{2}$ ) were placed on both sides of the membrane, and were then hot-pressed at $2 \mathrm{kN}$ and $130^{\circ} \mathrm{C}$ for $1 \mathrm{~min}$ to fabricate the MEAs.

\subsection{Structural analysis of electrodes}

Laser diffraction method (Sysmex-Matersizer 2000) was employed to determine the catalyst agglomerate size distributed in the catalyst ink. The primary and secondary pore structures of the MEA electrodes were investigated by mercury porosimetry (Auto Pore 9520, Micromeritics Instrument Corp.) and bubble point tests (Perm porometer, PMI), respectively, to determine the effect of homogenization time on the electrode microstructure. To observe macroscopic changes in the morphology of catalyst layers prepared with different agglomerate sizes, scanning electron microscopy (SEM) was employed to examine the surface of the electrodes.

\subsection{Electrochemical measurements}

Pure $\mathrm{H}_{2}$ and $\mathrm{N}_{2}$ gases were bubbled through deionized water baths at $58^{\circ} \mathrm{C}$ to achieve $90 \%$ relative humidity $(\mathrm{RH})$ for a cell temperature of $60^{\circ} \mathrm{C}$. The humidified $\mathrm{H}_{2}$ and $\mathrm{N}_{2}$ gases were further supplied to the anode and cathode sides at flow rates of 100 and

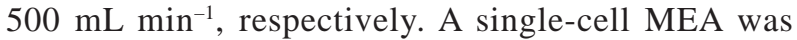
connected to a potentio/galvanostat (P/G stat) (HZ5000: HAG3001, Hokuto Denko Co. Ltd.) for the in situ $\mathrm{CV}$ test under gas-phase conditions at a sweep rate of $20 \mathrm{mV} \mathrm{s}^{-1}$ (Morikawa et al., 2004; Sasikumar et al., 2004). From the result of the CV test, an electrochemical parameter known as the electrochemical surface area ( $E S A, \mathrm{~cm}^{2}$-Pt $\mathrm{cm}^{-2}$-electrode), which was used to estimate the exchange current density per unit surface area of Pt was estimated.

\subsection{Performance tests of single-cell MEAs}

The MEA performance, namely polarization curves and ohmic loss, was tested under the same conditions stated above, except that $\mathrm{O}_{2}$ was fed into the cathode instead of $\mathrm{N}_{2}$. The polarization curves were obtained using a galvanostat (HJ1010SM8A, Hokuto Denko Co. Ltd.), and the ohmic loss was measured on a HZ3000: HAG5010 potentio/galvanostat using the current interruption method.

\section{Results and Discussion}

First, experimental analyses of the catalyst structures were carried out to verify the validity of cylindrical secondary pore-based models. Then, the ORR activity of the catalyst was determined to support our idea on the separation of structural and reaction parameters.

\subsection{Determination of catalyst agglomerate size in catalyst ink}

The agglomerate size distribution in catalyst inks homogenized for different periods of time is depicted in Figure 3. From the results, two main peaks were observed: one at around $0.1 \mu \mathrm{m}$ and the other above $1 \mu \mathrm{m}$. Kim et al. (2004) studied the particle size dis-

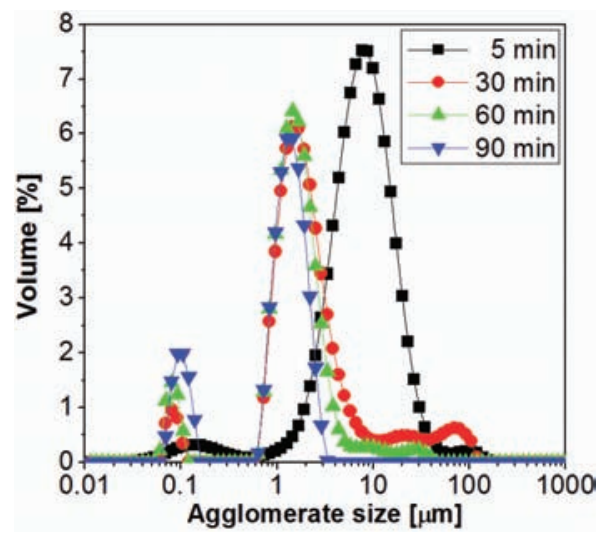

Fig. 3 Agglomerate size distributions of catalyst inks homogenized for various time periods

tribution of Nafion ${ }^{\circledR}$ ionomer using the dynamic light scattering (DLS) method and observed changes in the peak position in the region corresponding to $0.04-0.8$ $\mu \mathrm{m}$. Thus, the first peak was believed to come from the particle size distribution of Nafion ${ }^{\circledR}$ ionomer in the dispersion solvent (Kim et al., 2004), for which similar results were also observed by Lim et al. (2006) As a result, the second peak was thought to contribute to the agglomerate size distribution. This clearly showed that by increasing homogenization time, the agglomerate size could be decreased.

\subsection{Effect of homogenization time on structure of MEA electrodes}

MEA electrodes fabricated from different catalyst inks, as stated in Section 3.1, were investigated by mercury porosimetry and bubble point test for determination of their primary and secondary pore sizes, respectively. The primary pore size distributions of the MEA electrodes measured by mercury porosimetry are presented in Figures 4(a) and (b). The mean primary pore size was unaffected by homogenization time, and thus the catalyst agglomerate size. The mean pore size of each electrode was approximately $60 \mathrm{~nm}$, which corresponded to the reference range proposed by Uchida et al. (1996) (20-40 nm). This implied that the present method of catalyst ink preparation (homogenization or ultrasonication) and the catalyst used herein (carbon-supported $\mathrm{Pt}$ ) prevented the penetration of Nafion ${ }^{\circledR}$ ionomer into primary pores of catalyst agglomerates. This could not be avoided even when the catalyst agglomerate size was significantly reduced.

Since the reliable data range of mercury porosimetry was $2-100 \mathrm{~nm}$, a bubble point test that would yield accurate results $100 \mathrm{~nm}$ was introduced to measure the secondary pore size, which was normally around 40-1000 $\mathrm{nm}$. The secondary pore size distributions of the examined electrodes are presented in Figure 5(a) (homogenization times of 5 and $30 \mathrm{~min}$ ) and Figure 5(b) (homogenization times of 60 and $90 \mathrm{~min}$ ). The mean secondary pore size tended to decrease with 

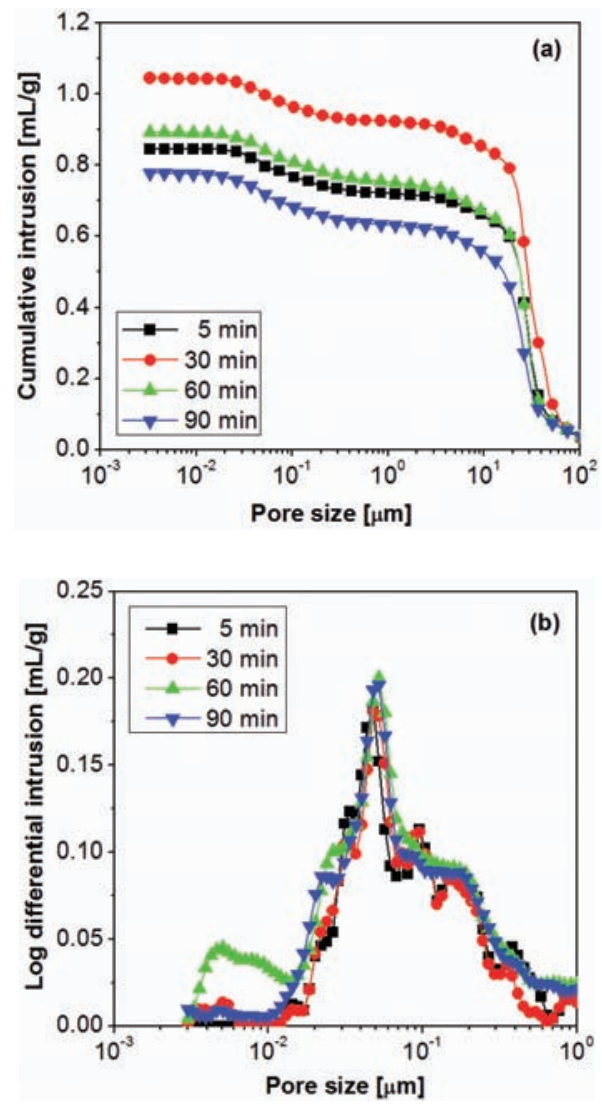

Fig. 4 Primary pore size distributions of the MEA electrodes measured by mercury porosimetry: (a) cumulative curves, and (b) differential curves

increasing homogenization time. As a result, the mean pore sizes, which corresponded to a large number of pores, were used as secondary pore sizes in the model simulation, namely 550, 430, 400, and $360 \mathrm{~nm}$ for homogenization times of 5, 30, 60, and $90 \mathrm{~min}$, respectively. The results obtained from mercury porosimetry and bubble point tests proved that the most utilizable Pt particles were present on the surface of secondary pores. Consequently, the assumption of cylindrical secondary pore-based model is valid, and by considering diffusion and reaction in secondary pores, those in the primary pores could be neglected.

From the decrease in agglomerate size in the catalyst ink and the decrease in secondary pore size, it can reasonably be speculated that the agglomerate size in the catalyst layer can actually be decreased by increasing the homogenization time. The effect of homogenization time on macroscopic changes in the morphology of the surface of the catalyst layer was investigated using SEM. Figures 6(a) and (b) represent SEM micrographs of the surface of the MEA electrodes homogenized for 5 and $90 \mathrm{~min}$, respectively. As is evident from the micrographs, small agglomeration (grey elements) and small secondary pore size (black ele-
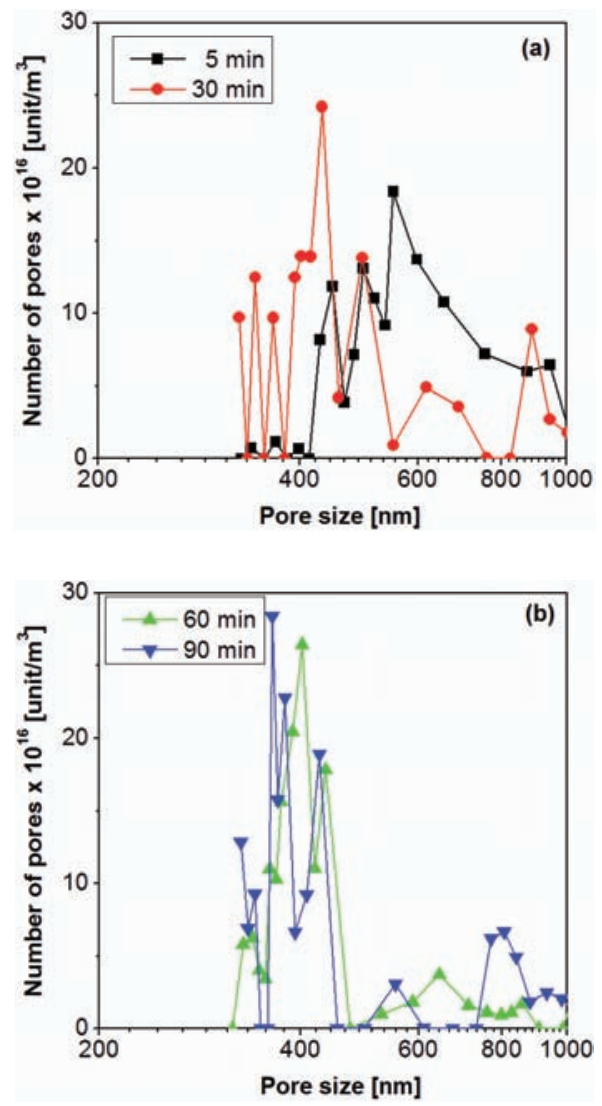

Fig. 5 Secondary pore size distributions of the MEA electrodes after homogenization for (a) 5 and $30 \mathrm{~min}$, and (b) 60 and $90 \mathrm{~min}$, as measured by bubble point tests

ments) with uniform distribution can be achieved by homogenizing the catalyst ink for a long period of time. This result concurs with that obtained from the bubble point tests showing a decrease in the secondary pore size.

Table 2 summarizes structural parameters of the catalyst layers, i.e., agglomerate size, and average primary and secondary pore sizes, as measured by the experiments described above.

\subsection{Determination of ORR activity from experi- ments}

4.3.1 Electrochemical surface area (ESA) and Pt utilization $\left(U_{\mathrm{Pt}}\right) \quad \mathrm{CV}$ tests were carried out to examine the variation in the $E S A\left[\mathrm{~cm}^{2}-\mathrm{Pt} \mathrm{cm}^{-2}\right.$-electrode] and $U_{\mathrm{Pt}}[\%]$ with homogenization time. $E S A$ and $U_{\mathrm{Pt}}$ can be calculated from the cyclic voltammograms (Figure 7) using the following equations:

$$
E S A=Q_{\mathrm{H}} / Q_{\mathrm{Pt}} \quad \text { and } \quad U_{\mathrm{Pt}}=E S A /\left(S \times A_{\mathrm{s}}\right)
$$

where $Q_{\mathrm{H}}\left[\mu \mathrm{C} \mathrm{cm}^{-2}\right.$-electrode $]$ is the electric charge for hydrogen desorption on the Pt catalyst after subtracting the double layer charge (left-upper peak in Figure 7). 


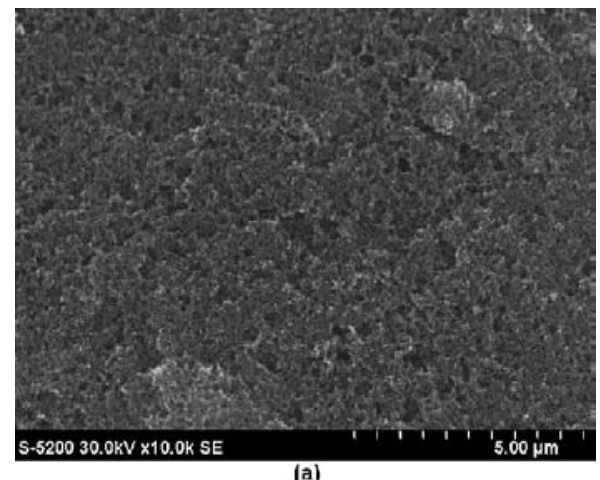

(a)

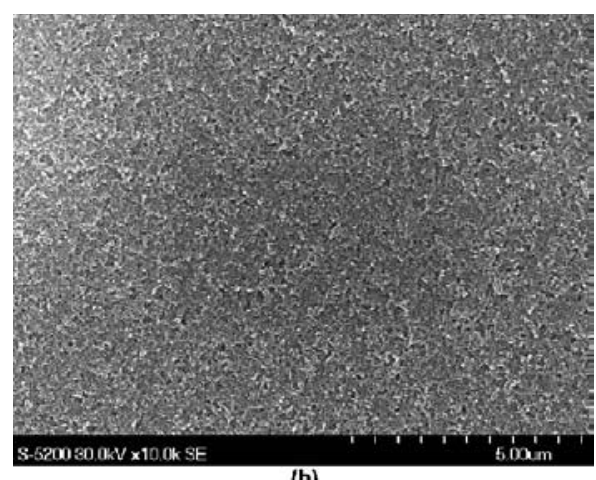

(b)

Fig. 6 SEM micrographs of the surface of MEA electrodes homogenized for (a) $5 \mathrm{~min}$ and (b) $90 \mathrm{~min}$

$Q_{\mathrm{Pt}}$ is the charge associated with the oxidation of atomic hydrogen on the smooth surface of polycrystalline $\mathrm{Pt}$, which is equal to $210 \mu \mathrm{C} \mathrm{cm} \mathrm{cm}^{-2}$-Pt (Watanabe and Motoo, 1975; Anger et al., 1989).

As shown in Figure 7, the area of the hydrogen desorption peak increased with increasing homogenization time, contributing to an improvement in ESA and $U_{\mathrm{Pt}}$. This was because with a longer homogenization time, smaller agglomerate size can be achieved, and the smaller agglomerates were better dispersed and bound to the Nafion ${ }^{\circledR}$ ionomer to form three-phase boundaries in the catalyst ink. In addition, when the agglomerate size was small, unused Pt catalyst existing mostly inside the agglomerate was reduced, leading to an increase in ESA and $U_{\mathrm{Pt}}$. The values of ESA and $U_{\mathrm{Pt}}$ of the MEAs are presented in Table 3, which summarizes reaction parameters obtained from experiments in this work.

4.3.2 Exchange current density per unit active surface area of Pt $\left(\underline{i}_{0, \mathrm{Pt}}\right) \quad$ As stated earlier, the main disadvantage in considering ORR activity in terms of current per unit surface area of the electrode $\left(i_{0}\right)$ or current per unit volume of the catalyst layer or agglomerate is that this reaction parameter takes the effect of structural parameters of the catalyst into account, e.g., agglomerate size, catalyst porosity, dispersion of electrolyte, etc. For this reason, various values of ORR
Table 2 A summary of structural parameters obtained from experiments for catalyst inks and MEAs prepared at different homogenization times

\begin{tabular}{lccc}
\hline $\begin{array}{l}\text { Homogenization } \\
\text { time }[\mathrm{min}]\end{array}$ & $\begin{array}{c}\text { Agglomerate } \\
\text { size }[\mathrm{mm}]\end{array}$ & $\begin{array}{c}\text { Primary pore } \\
\text { size }[\mathrm{nm}]\end{array}$ & $\begin{array}{c}\text { Secondary pore } \\
\text { size }[\mathrm{nm}]\end{array}$ \\
\hline 5 & 9.7 & 74 & 550 \\
30 & 4.8 & 64 & 430 \\
60 & 1.4 & 68 & 400 \\
90 & 0.6 & 60 & 360 \\
\hline
\end{tabular}

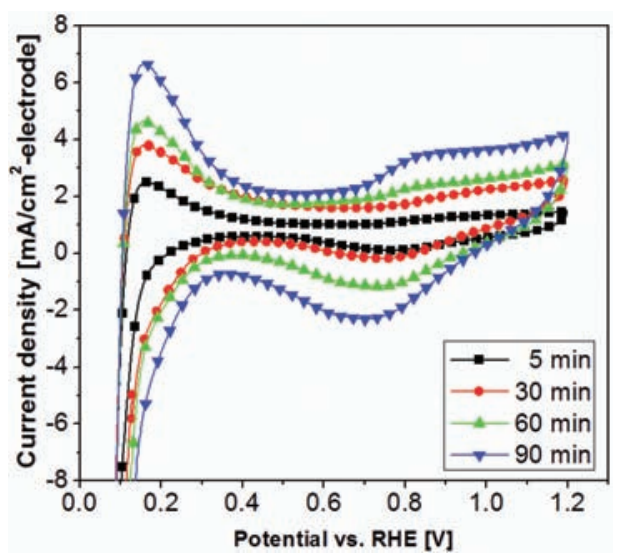

Fig. 7 Cyclic voltammograms of MEAs prepared at different homogenization times at a sweep rate of $20 \mathrm{mV} \mathrm{s}^{-1}$

activity are presented for the same catalyst in previous models. As a result, comparison of the performance of different catalysts and catalyst structures becomes difficult, and this contributes to the inefficient use of modeling approaches for designing a high-performance catalyst and catalyst structure for PEFCs. To avoid the influence of catalyst structure and to study the catalyst ORR activity more effectively, the exchange current density is considered per unit active surface area of $\mathrm{Pt}$ $\left(i_{0, \mathrm{Pt}}\left[\mathrm{A} \mathrm{cm} \mathrm{cm}^{-2} \mathrm{Pt}\right]\right)$, and is calculated as follows:

$$
i_{0, \mathrm{Pt}}=i_{0} / E S A
$$

Polarization curves obtained for the MEAs used in this work were measured by the cell performance test and are depicted in Figure 8. It was apparent that the MEA prepared at the longest homogenization time (90 min, in other words, the smallest catalyst agglomerate size) delivered the best performance, and vice versa. This was because decrease in the agglomerate size resulted in an improvement of the morphology of the catalyst layer. The main reason for this is the improvement in $U_{\mathrm{Pt}}$ described earlier in Section 4.3.1. As is evident from the SEM micrographs, with small pores and small agglomerates with uniform distribution, the surface of the catalyst layer became smooth. This ensured the good contact between the electrodes and the membrane in MEA 
Table 3 A summary of reaction parameters obtained from experiments for MEAs prepared from different homogenization times

\begin{tabular}{llllll}
\hline Parameter & Unit & MEA-A & MEA-B & MEA-C & MEA-D \\
\hline Homogenization time & $\mathrm{min}$ & 5 & 30 & 60 & 90 \\
Catalyst loading, $S$ & $\mathrm{mg}-\mathrm{Pt} \mathrm{cm}^{-2}$-electrode & 0.3 & 0.3 & 0.3 & 0.4 \\
Specific surface area of Pt, $A_{\mathrm{s}}$ & $\mathrm{m}^{2}-\mathrm{Pt} \mathrm{g}^{-1}-\mathrm{Pt}$ & 132.2 & 132.2 & 132.2 & 132.2 \\
Electrochemical surface area, $E S A$ & $\mathrm{~cm}^{2}-\mathrm{Pt} \mathrm{cm}^{-2}$-electrode & 50 & 91 & 103 & 169 \\
Pt utilization, $U_{\mathrm{Pt}}$ & $\%$ & 16 & 22 & 25 & 32 \\
Resistance, $R$ & $\mathrm{~mW} \mathrm{~cm}{ }^{2}$-electrode & 113 & 102 & 86 & 72 \\
Open circuit voltage, $O C V$ & $\mathrm{~V}$ & 1.05 & 1.06 & 1.05 & 1.05 \\
Exchange current density, $i_{0, \mathrm{Pt}}$ & $\mathrm{mA} \mathrm{cm}{ }^{-2}-\mathrm{Pt}$ & 2.8 & 2.3 & 2.8 & 2.9 \\
\hline
\end{tabular}

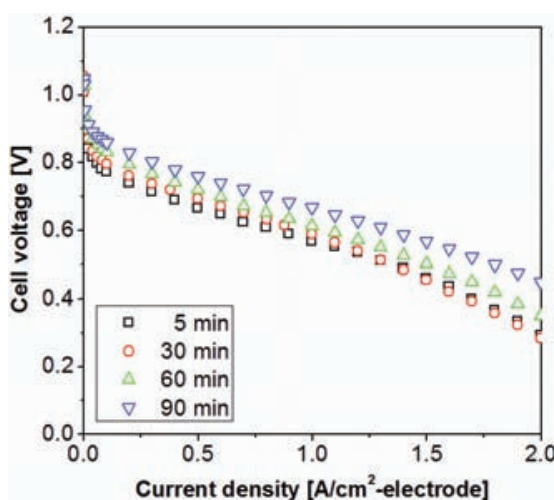

Fig. 8 Polarization curves for selected MEAs prepared at different homogenization times. Cell temperature was $60^{\circ} \mathrm{C}$

fabrication. As a result, proton conductivity at catalyst layer/electrolyte interface was improved, and thus the ohmic loss was reduced (Table 3).

From the results of the cell performance tests, Tafel plots for those MEAs were analyzed and depicted in Figure 9. The values of $i_{0}$ were estimated at potential $=0$ from the linear extrapolation of a Tafel slope of about $-2.3 \times 2 R T / F$ (Langmuir region), which corresponded to the potential range of approximately $0.7-$ 0.85 V vs. RHE (Sepa et al., 1986; Kabbabi et al., 1994; Limjeerajarus et al., 2009). Calculation of $i_{0}$ was performed in this potential range in order to avoid the effect of adsorbed oxygen-containing species, which caused the decrease in ORR rate by inhibiting the $\mathrm{O}_{2}$ gas from the reaction site. Previous works have showed that very low adsorption of oxygen-containing species is detected in this potential range (Damjanovic and Brusic, 1967; Sepa et al., 1981; Parthasarathy et al., 1991; Tada et al., 2007; Limjeerajarus et al., 2008, 2009). Meanwhile, in very high-potential region (at potentials above $0.85 \mathrm{~V}$ vs. RHE), the Tafel slope rapidly decreased due to the large number of the adsorbed oxygen-containing species. Hence, the data in the very high-potential region was not used for calculating $i_{0, \mathrm{Pt}}$ in the present work. Consequently, the values of $i_{0}$ were converted to $i_{0, \mathrm{Pt}}$ using Eq. (50).

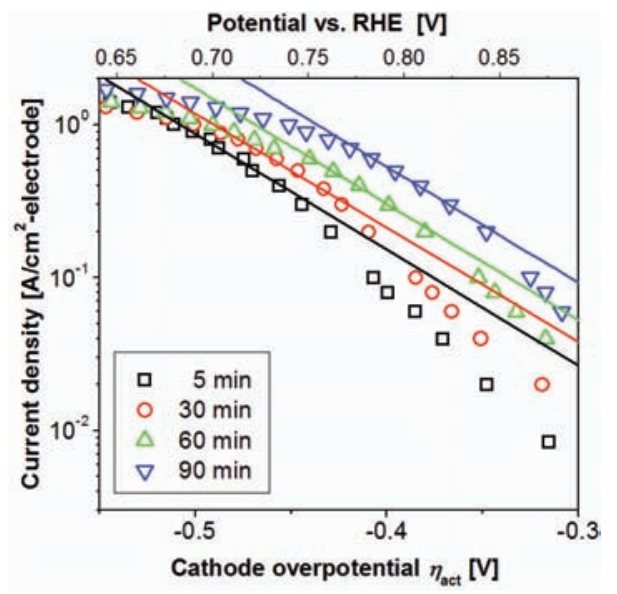

Fig. 9 Tafel plots for selected MEAs prepared at different homogenization times; symbols refer to experimental values, and solid lines represent Tafel slopes at $-2.3 \times 2 R T / F$, which were used in the calculation of $i_{0}$. Cell temperature was $60^{\circ} \mathrm{C}$

The dependence of $i_{0, \mathrm{Pt}}$ on the catalyst agglomerate size (Figure 10) indicated that the values of $i_{0, \mathrm{Pt}}$ remains almost constant at $2.7 \times 10^{-6} \mathrm{~A} \mathrm{~cm}^{-2}$-Pt, regardless of the agglomerate size. The average value of $i_{0, \mathrm{Pt}}$ also corresponded to that of catalysts with different $\mathrm{Pt} / \mathrm{C}$ ratios reported in our previous work, i.e., $2.6 \times 10^{-6}$ A cm ${ }^{-2}$-Pt (Limjeerajarus et al., 2009). The constant value of $i_{0, \mathrm{Pt}}$ (even when agglomerate size was significantly reduced) indicated that the reaction parameters of same types of catalyst should be identical, regardless of the catalyst structure. Therefore, this experimental result coincided with our proposal that structural and reaction parameters of a catalyst should be independently considered in PEFC modeling.

\subsection{Model simulation and validation}

Simulations were performed using the structural and reaction parameters presented in Tables 2 and 3, and the physical parameters and operating conditions presented in Table 4. In model validation, simulations were carried out for all four homogenization times mentioned earlier. The values of secondary pore size $\left(R_{\text {pore }}\right)$ obtained from 
Table 4 A summary of simulation parameters used in model validation

\begin{tabular}{lllll}
\hline Parameter & Value & & Parameter & Value \\
\cline { 1 - 2 } \cline { 5 - 6 }$r_{\mathrm{cb}}[\mathrm{m}]$ & $1.5 \times 10^{-8}$ & & $L_{\text {mem }}[\mathrm{m}]$ & $1.8 \times 10^{-4}$ \\
$r_{\mathrm{Pt}}[\mathrm{m}]$ & $1.5 \times 10^{-9}$ & & $M[\mathrm{wt} \%$ & 46.5 \\
$\rho_{\mathrm{cb}}\left[\mathrm{g} \mathrm{m}^{-3}\right]$ & $2.25 \times 10^{6}$ & & $A\left[\mathrm{~cm}^{2}\right]$ & 5 \\
$\rho_{\mathrm{Pt}}\left[\mathrm{g} \mathrm{m}^{-3}\right]$ & $2.145 \times 10^{7}$ & & $P^{\mathrm{t}}[\mathrm{Pa}]$ & $1.13 \times 10^{5}$ \\
$l^{\text {poly }}[\mathrm{m}]$ & $8 \times 10^{-8}$ & & $D_{\mathrm{w}}^{\text {gas }}\left[\mathrm{m}^{2} \mathrm{~s}^{-1}\right]$ & $4 \times 10^{-5}$ \\
$l_{\mathrm{DL}}[\mathrm{m}]$ & $5 \times 10^{-5}$ & & $D_{\mathrm{O}_{2}}^{\text {gas }}\left[\mathrm{m}^{2} \mathrm{~s}^{-1}\right]$ & $3.52 \times 10^{-5}$ \\
$\varepsilon_{\mathrm{DL}}[-]$ & 0.6 & & $D_{\mathrm{w}}^{\text {poly }}\left[\mathrm{m}^{2} \mathrm{~s}^{-1}\right]$ & $4.86 \times 10^{-10}$ \\
$\varepsilon_{\mathrm{CL}}[-]$ & $0.4-0.5$ & & $D_{\mathrm{O}_{2}}^{\text {poly }}\left[\mathrm{m}^{2} \mathrm{~s}^{-1}\right]$ & $5.17 \times 10^{-10}$ \\
$U_{\mathrm{a}}\left[\mathrm{m}^{3} \mathrm{~s}^{-1}\right]$ & $1.67 \times 10^{-6}$ & & $C_{\text {ref }}\left[\mathrm{mol} \mathrm{m}^{-3}\right]$ & 0.88 \\
$U_{\mathrm{c}}\left[\mathrm{m}^{3} \mathrm{~s}^{-1}\right]$ & $8.33 \times 10^{-6}$ & & $\sigma_{\mathrm{e}}\left[\mathrm{S} \mathrm{m}^{-1}\right]$ & $10^{4}$ \\
\hline & & & &
\end{tabular}

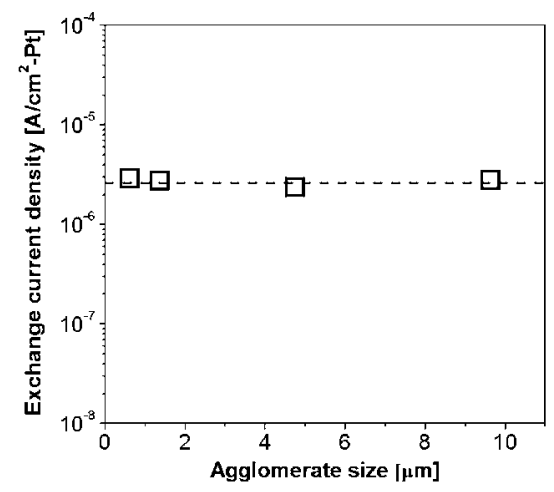

Fig. 10 Dependence of ORR activity $\left(i_{0, \mathrm{Pt}}\right)$ at a Tafel slope of about $-2.3 \times 2 R T / F$ on catalyst agglomerate size

the bubble point tests were considered to be 550, 430, 400 , and $360 \mathrm{~nm}$ for homogenization times of 5, 30, 60 , and $90 \mathrm{~min}$, respectively. The values of $U_{\mathrm{Pt}}$ obtained from the CV tests varied in the range of $16-35 \%$ for homogenization times of 5-90 min. Experimental results revealed that the ORR activity was identical for each catalyst, regardless of the catalyst structure. Therefore, the average value of ORR activity $i_{0 . \mathrm{Pt}}$, i.e., $2.7 \times 10^{-6} \mathrm{~A} \mathrm{~cm}^{-2}-\mathrm{Pt}$ was used for all simulations. I-V cell performance obtained from simulations was then compared with the experimental performance; the comparison results are shown in Figure 11.

Considering validation results in the entire potential region shown in Figure 11, the simulation results obtained with the developed model were in good correspondence with the experimental results. This implied that a PEFC model has been successfully developed by separately considering structural and reaction parameters. In addition, unlike previous models, the present model can be used to study the effect of each parameter individually without taking into account the influence of other parameters. Therefore, the developed model can be employed as a useful tool for future de-

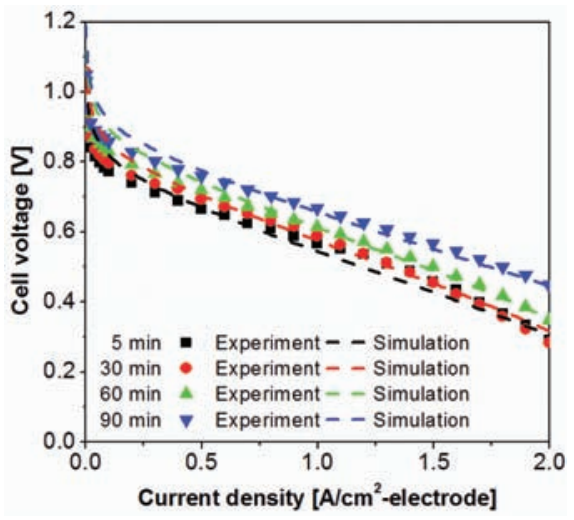

Fig. 11 Comparison of cell performance of MEAs prepared at different homogenization times, as obtained from simulation and experiments

velopment of catalysts and the design of catalyst structures.

To study the effect of each parameter on the PEFC cell performance, sensitivity analysis of the parameters used in the model was carried out. In brief, the simulation results showed that reaction parameters such as ORR activity have a significant effect on the cell performance in the high-potential region (above $0.7 \mathrm{~V}$ ). On the contrary, structural parameters such as electrochemical surface area and secondary pore size affect the cell performance in the low-potential region. These simulation results are in concurrence with those reported by other research groups (Wang, 2004; Weber and Newman, 2004a) that the high-potential and the low-potential regions are well known as the reaction dominant region and the mass-transfer limitation dominant region, respectively.

However, at potentials above $0.7 \mathrm{~V}$ (Figure 11), the developed model overestimated the cell performance, and the discrepancy between simulation and experimental results increased with the increasing potential. This overestimation can be explained by the lack of consideration of effect of oxygen-containing species adsorbed on the Pt surface area, which contributed to decrease in cell performance in the high-potential region (Damjanovic and Brusic, 1967; Sepa et al., 1981; Limjeerajarus et al., 2008). According to previous works (Siegel et al., 2003; Carnes and Djilali, 2005), this effect can be taken into account by using two values of $i_{0}$ for the two different Tafel slope regions (i.e., $-2.3 R T / F$ in the high-potential region and $-2.3 \times 2 R T / F$ in the low-potential region). However, the aim of this work is to focus on the macroscopic structures of the catalyst layers, and thus only one value of $i_{0}$ for a Tafel slope of about $-2.3 \times 2 R T / F$ was used. To construct more accurate models in the future, such microscopic reaction phenomenon should be taken into consideration. By separately considering structural and reaction 
parameters, the effect of oxygen-containing species can be easily introduced into PEFC modeling as a reaction parameter, which is now being developed in our group.

\section{Conclusions}

In the present work, a PEFC model that focuses on reactions and transport phenomena in the catalyst layer has been systematically developed. The structural and reaction parameters were independently considered in the model, in which ORR activity was expressed as current per unit active surface area of $\mathrm{Pt}\left[\mathrm{A} \mathrm{cm}^{-2}-\mathrm{Pt}\right]$. Thus, the developed model can be used to demonstrate the effect of each parameter on the cell performance without taking into the influence of other parameters, which occurs in previous models and in experimental approaches. This modeling approach was supported by the experimental results, according to which the ORR activity $\left[\mathrm{A} \mathrm{cm} \mathrm{cm}^{-2} \mathrm{Pt}\right.$ ] remained almost constant for the same catalyst types, regardless of the agglomerate size. In addition, the results of mercury porosimetry showed that primary pore size remained unchanged even with a decrease in the agglomerate size. This confirmed that in the $\mathrm{Pt} / \mathrm{C}$ catalyst, penetration of $\mathrm{Nafion}^{\circledR}$ ionomer into primary pores was restricted, and thus the diffusion and reaction in the primary pores of the agglomerates were negligible. As a result, for PEFC MEAs prepared with $\mathrm{Pt} / \mathrm{C}$ catalysts, the assumption of cylindrical secondary pore-based model was valid, and the primary pore models could be neglected to make the model less complicated. This finding coincided with the model validation, in which the simulation results of cell performance were in good agreement with the experimental results, except in the very high-potential region. Further improvement of the model in the highpotential region is in progresss by considering the effect of adsorbed oxygen-containing species. Therefore, the developed model and the proposed modeling methodology can be used to predict the cell performance and to develop system and material designs for PEFCs.

\section{Acknowledgements}

The authors are grateful for financial support provided by the New Energy and Industrial Technology Development Organization (NEDO), Japan. We also appreciate the technical assistance from Sysmex Corp. for conducting laser diffraction tests on our catalyst ink samples.

\begin{tabular}{llrr}
\multicolumn{2}{l}{ Nomenclature } & \\
$A$ & $=$ & geometric area & {$\left[\mathrm{m}^{2}\right]$} \\
$A_{\mathrm{s}}$ & $=$ & specific surface area of Pt & {$\left[\mathrm{m}^{2} \mathrm{~g}^{-1}\right]$} \\
$a$ & $=$ & water activity in polymer & {$[-]$} \\
$b$ & $=$ & Tafel slope & {$[\mathrm{V} \mathrm{decade}]$} \\
$C_{i}$ & $=$ & reactant gas concentration of species $i$ & {$\left[\mathrm{~mol} \mathrm{~m}^{-3}\right]$} \\
$D_{i}$ & $=$ & diffusion coefficient of species $i$ & {$\left[\mathrm{~m}^{2} \mathrm{~s}^{-1}\right]$} \\
$E S A$ & $=$ & electrochemical surface area & \\
& & & {$\left[\mathrm{cm}^{2}-\mathrm{Pt} \mathrm{cm}^{-2}\right.$-electrode] } \\
$E_{0}$ & $=$ & theoretical electromotive force & {$[\mathrm{V}]$} \\
$F$ & $=$ & faraday's constant, $=96485$ & {$\left[\mathrm{C} \mathrm{mol}^{-1}\right]$}
\end{tabular}

$=$ total current density per electrode area

[A $\mathrm{cm}^{-2}$-electrode]

$=$ local current density per secondary pore

$=$ exchange current density per unit surface of electrode [A $\mathrm{cm}^{-2}$-electrode]

$=$ exchange current density per unit surface of $\mathrm{Pt}$

$\quad\left[\mathrm{mol} \mathrm{m}^{-2} \mathrm{~s}^{-1}\right]$

$=$ thickness of catalyst layer

$=$ thickness

$\left[\mathrm{mol} \mathrm{m}^{-2} \mathrm{~s}^{-1}\right]$
$[\mathrm{m}]$

molecular weight

$\mathrm{Pt} / \mathrm{C}$ mass ratio of the catalyst

quantity

quantity of platinum per one carbon

pressure of species $i \quad\left[\mathrm{~N} \mathrm{~m}^{-2}\right]$

supplied rate of reactant gas $\quad\left[\mathrm{mol} \mathrm{s}^{-1}\right]$

ideal gas constant, $=8.314 \quad\left[\mathrm{~J} \mathrm{~mol}^{-1} \mathrm{~K}^{-1}\right]$

radius of one particle [m]

Pt catalyst loading [ $\quad\left[\mathrm{g} \mathrm{cm}^{-2}\right.$-electrode $]$

absolute temperature [K]

volumetric flow rate of fuel gas $\left[\mathrm{m}^{3} \mathrm{~s}^{-1}\right]$

Pt utilization [\%]

reaction rate [A m $\left.{ }^{-2}\right]$

weight of one particle [g]

= normalized distance from the diffusion layer/catalyst layer interface to the catalyst layer/membrane interface [-]

$=$ molar ratio $\quad[-]$

$=$ number of electrons transferred per reaction $[-]$

$=$ charge transfer coefficient $[-]$

$=$ parameter of Henry's law $[-]$

$=$ porosity $[-]$

$=$ overpotential [V]

$=$ water content, $=\left[\mathrm{H}_{2} \mathrm{O}\right] /\left[\mathrm{SO}_{3}^{-}\right]$

$=$ electro-osmotic drag coefficient in fully hydrated state, $=\mathrm{H}_{2} \mathrm{O} / \mathrm{H}^{+} \quad[-]$

$=$ electro-osmotic drag coefficient in partially hydrated state, $=\mathrm{H}_{2} \mathrm{O} / \mathrm{H}^{+} \quad[-]$

$=$ density $\quad\left[\mathrm{g} \mathrm{m}^{-3}\right]$

$=$ conductivity $\quad\left[\mathrm{S} \mathrm{m}^{-1}\right]$

$=$ tortuosity [-]

= fitting parameter for electro-osmotic drag coefficient

$=$ local potential

$=$ anode

activation

bubbler

$=$ catalyst layer

$=$ cathode

carbon

= hydrogen crossover

$=$ diffusion layer

$=$ electron in electron conductive phase

$=$ hydrogen

$=$ ohmic loss

$=$ species index

$=$ electrolyte membrane

oxygen

platinum

proton in electrolyte phase

secondary pores of the catalyst layer

reference

one sheet of carbon per $\mathrm{cm}^{2}$-electrode

water 


$\begin{array}{ll}\text { < Superscript }> \\ \text { diff } & =\text { diffusion by the concentration gradient } \\ \text { e } & =\text { electron-conducting phase } \\ \text { eff } & =\text { effective } \\ \text { gas } & =\text { gas phase } \\ \text { gen } & =\text { generated from reaction } \\ \text { in } & =\text { inlet of fuel gas } \\ \text { os } & =\text { electro-osmosis } \\ \text { out } & =\text { outlet of fuel gas } \\ \text { poly } & =\text { proton-conducting polymer electrolyte } \\ \text { poly0 } & =\text { gas/electrolyte interface } \\ \text { polyL } & =\text { electrolyte/Pt interface } \\ \text { t } & =\text { total } \\ \text { trans } & =\text { net water flux transporting between anode and cath- } \\ & \end{array}$

\section{Literature Cited}

Acosta, M., C. Merten, G. Eigenberger, H. Class, R. Helmig, B. Thoben and H. Müller-Steinhagen; "Modeling Non-Isothermal TwoPhase Multicomponent Flow in the Cathode of PEM Fuel Cells," J. Power Sources, 159, 1123-1141 (2006)

Anger, G., H. F. Berger, M. Luger, S. Feistritzer, A. Winkler and K. D. Rendulic; "Microfacets of the $(1 \times 2)$ Reconstructed Pt(110) Surface Seen in the Adsorption Dynamics of $\mathrm{H}_{2}$," Surf. Sci., 219, L583-L589 (1989)

Carnes, B. and N. Djilali; "Systematic Parameter Estimation for PEM Fuel Cell Models," J. Power Sources, 144, 83-93 (2005)

Damjanovic, A. and V. Brusic; "Electrode Kinetics of Oxygen Reduction on Oxide-Free Platinum Electrodes," Electrochim. Acta, 12, 615-628 (1967)

Eikerling, M.; "Water Management in Cathode Catalyst Layers of PEM Fuel Cells," J. Electrochem. Soc., 153, E58-E70 (2006)

Hinatsu, J. T., M. Mizuhata and H. Takenaka; "Water Uptake of Perfluorosulfonic Acid Membranes from Liquid Water and Water Vapor," J. Electrochem. Soc., 141, 1493-1498 (1994)

Kabbabi, A., F. Gloaguen, F. Andolfatto and R. Durand; "Particle Size Effect for Oxygen Reduction and Methanol Oxidation on $\mathrm{Pt} / \mathrm{C}$ inside a Proton Exchange Membrane," J. Electroanal. Chem., 373, 251-254 (1994)

Karan, K.; "Assessment of Transport-Limited Catalyst Utilization for Engineering of Ultra-Low Pt Loading Polymer Electrolyte Fuel Cell Anode," Electrochem. Commun., 9, 747-753 (2007)

Kim, J. H., H. Y. Ha, I. H. Oh, S. A. Hong and H. I. Lee; "Influence of the Solvent in Anode Catalyst Ink on the Performance of a Direct Methanol Fuel Cell," J. Power Sources, 135, 29-35 (2004)

Lim, C., R. G. Allen and K. Scott; "Effect of Dispersion Methods of an Unsupported Pt-Ru Black Anode Catalyst on the Power Performance of a Direct Methanol Fuel Cell," J. Power Sources, 161, 11-18 (2006)

Limjeerajarus, N., T. Yanagimoto, T. Yamamoto, T. Ito and T. Yamaguchi; "Quantitative Analysis of Oxygen-Containing Species Adsorbed on the Pt Surface of a Polymer Electrolyte Fuel Cell Membrane Electrode Assembly Electrode Using Stripping Voltammetry," J. Power Sources, 185, 217-221 (2008)

Limjeerajarus, N., T. Yanagimoto, T. Yamamoto, H. Ohashi, T. Ito and T. Yamaguchi; "Analysis of Oxygen Reduction Reaction Activity of Pt/C Catalysts for Actual PEFC MEAs," J. Chem. Eng. Japan, 42, 39-46 (2009)

Lin, G., W. He and T. V. Nguyen; "Modeling Liquid Water Effects in the Gas Diffusion and Catalyst Layers of the Cathode of a PEM Fuel Cell," J. Electrochem. Soc., 151, A1999-A2006 (2004)

Maggio, G., V. Recupero and L. Pino; "Modeling Polymer Electrolyte Fuel Cells: an Innovative Approach," J. Power Sources, 101, 275-286 (2001)

Meng, H. and C. Y. Wang; "Model of Two-Phase Flow and Flooding Dynamics in Polymer Electrolyte Fuel Cells," J. Electrochem.
Soc., 152, A1733-A1741 (2005)

Morikawa, H., N. Tsuihiji, T. Mitsui and K. Kanamura; "Preparation of Membrane Electrode Assembly for Fuel Cell by Using Electrophoretic Deposition Process," J. Electrochem. Soc., 151, A1733-A1737 (2004)

Murgia, G., L. Pisani, A. K. Shukla and K. Scott; "A Numerical Model of a Liquid-Feed Solid Polymer Electrolyte DMFC and Its Experimental Validation," J. Electrochem. Soc., 150, A1231A1245 (2003)

Parthasarathy, A., C. R. Martin and S. Srinivasan; "Investigations of the $\mathrm{O}_{2}$ Reduction Reaction at the Platinum/Nafion ${ }^{\circledR}$ Interface Using a Solid-State Electrochemical Cell," J. Electrochem. Soc., 138, 916-921 (1991)

Ren, X. and S. Gottesfeld; "Electro-Osmotic Drag of Water in Poly(Perfluorosulfonic Acid) Membranes," J. Electrochem. Soc., 148, A87-A93 (2001)

Rowe, A. and X. G. Li; "Mathematical Modeling of Proton Exchange Membrane Fuel Cells," J. Power Sources, 102, 82-96 (2001)

Sasikumar, G., J. W. Ihm and H. Ryu; "Dependence of Optimum Nafion Content in Catalyst Layer on Platinum Loading," J. Power Sources, 132, 11-17 (2004)

Sepa, D. B., M. V. Vojnovic and A. Damjanovic; "Reaction Intermediates as a Controlling Factor in the Kinetics and Mechanism of Oxygen Reduction at Platinum Electrodes," Electrochim. Acta, 26, 781-793 (1981)

Sepa, D. B., M. V. Vojnovic, L. M. Vračar and A. Damjanovic; “Apparent Enthalpies of Activation of Electrodic Oxygen Reduction at Platinum in Different Current Density Regions-I. Acid Solution," Electrochim. Acta, 31, 91-96 (1986)

Shah, A. A., G.-S. Kim, W. Gervais, A. Young, K. Promislow, J. Li and S. Ye; "The Effects of Water and Microstructure on the Performance of Polymer Electrolyte Fuel Cells," J. Power Sources, 160, 1251-1268 (2006)

Siegel, N. P., M. W. Ellis, D. J. Nelson and M. R. von Spakovsky; "Single Domain PEMFC Model Based on Agglomerate Catalyst Geometry," J. Power Sources, 115, 81-89 (2003)

Society of Chemical Engineers, Japan; Chemical Engineering HandBook (Kagaku Kogaku Benran), 6th ed., Maruzen, Tokyo, Japan (1999)

Springer, T. E., T. A. Zawodzinski and S. Gottesfeld; "Polymer Electrolyte Fuel Cell Model," J. Electrochem. Soc., 138, 2334-2342 (1991)

Stamenkovic, V., B. S. Mun, K. J. J. Mayrhofer, P. N. Ross, N. M. Markovic, J. Rossmeisl, J. Greeley and J. K. Nørskov; "Changing the Activity of Electrocatalysts for Oxygen Reduction by Tuning the Surface Electronic Structure," Angew. Chem. Int. Ed., 45, 2897-2901 (2006)

Tada, M., S. Murata, T. Asakoka, K. Hiroshima, K. Okumura, H. Tanida, T. Uruga, H. Nakanishi, S.-I. Matsumoto, Y. Inada, M. Nomura and Y. Iwasawa; "In situ Time-Resolved Dynamic Surface Events on the Pt/C Cathode in a Fuel Cell under Operando Conditions," Angew. Chem. Int. Ed., 46, 4310-4315 (2007)

Thampan, T., S. Malhotra, H. Tang and R. Datta; "Modeling of Conductive Transport in Proton-Exchange Membranes for Fuel Cells," J. Electrochem. Soc., 147, 3242-3250 (2000)

Uchida, M., Y. Fukuoka, Y. Sugawara, N. Eda and A. Ohta; "Effects of Microstructure of Carbon Support in the Catalyst Layer on the Performance of Polymer-Electrolyte Fuel Cells," J. Electrochem. Soc., 143, 2245-2252 (1996)

Wang, C. Y.; "Fundamental Models for Fuel Cell Engineering," Chem. Rev., 104, 4727-4766 (2004)

Wang, Q., M. Eikerling, D. Song and Z. Liu; "Structure and Performance of Different Types of Agglomerates in Cathode Catalyst Layers of PEM Fuel Cells," J. Electroanal. Chem., 573, 61-69 (2004)

Wang, Y. and C. Y. Wang; "A Nonisothermal, Two-Phase Model for Polymer Electrolyte Fuel Cells," J. Electrochem. Soc., 153, A1193-A1200 (2006) 
Watanabe, M. and S. Motoo; "Electrocatalysis by Ad-Atoms: Part III. Enhancement of the Oxidation of Carbon Monoxide on Platinum by Ruthenium Ad-Atoms," J. Electroanal. Chem., 60, 275283 (1975)

Weber, A. Z. and J. Newman; "Modeling Transport in Polymer-Electrolyte Fuel Cells," Chem. Rev., 104, 4679-4726 (2004a)
Weber, A. Z. and J. Newman; "Transport in Polymer-Electrolyte Membranes II. Mathematical Model," J. Electrochem. Soc., 151, A311-A325 (2004b)

You, L. and H. Liu; "A Two-Phase Flow and Transport Model for PEM Fuel Cells,” J. Power Sources, 155, 219-230 (2006) 